\title{
THE METHODOLOGY OF INTERDISCIPLINARY RESEARCH AND THE SCIENCE OF INTERNATIONAL LAW
}

\author{
Emil A. Karakulyan \\ Lobachevsky State University of Nizhni Novgorod, Nizhny Novgorod, Russian Federation
}

Introduction: interdisciplinarity comes in two forms: as a tool in relation to the subject of research and as a methodology of interdisciplinarity. The question of the need to develop a general theory of interdisciplinarity and the theoretical basis for its application in the science of international law is raised. Methods: historicism, system, analysis and comparative law. Results: an attempt to systematize the interdisciplinary methods and approaches, examples of interdisciplinarity in the development of new systemic and author's approaches and terms within the framework of international legal studies. Conclusions: the essential connection between the issues of interdisciplinarity and the grounds of scientific novelty, which are important in terms of specific relationship between the theory of international law and its subject, is established.

Key words: theory of interdisciplinarity, science of international law, theory of integration, professional competence, problems of higher education.

Citation. Karakulyan E.A. The Methodology of Interdisciplinary Research and the Science of International Law. Legal Concept, 2019, vol. 18, no. 4, pp. 146-152. (in Russian). DOI: https://doi.org/10.15688/lc.jvolsu.2019.4.20

\section{МЕТОДОЛОГИЯ МЕЖДИСЦИПЛИНАРНЫХ ИССЛЕДОВАНИЙ И НАУКА МЕЖДУНАРОДНОГО ПРАВА}

\section{Эмиль Альбертович Каракулян}

Национальный исследовательский Нижегородский государственный университет им. Н.И. Лобачевского, г. Нижний Новгород, Российская Федерация

Введение: известно, что междисциплинарность выступает в двух формах: как инструмент в отношении предмета исследования и методология междисциплинарности. В статье ставится вопрос о необходимости развития общей теории междисциплинарности и теоретических основаниях ее применения в рамках науки международного права. Методы: в исследовании использованы общенаучные методы историзма, системности, анализа, а также сравнительно-правовой метод. Результаты: предпринята попытка систематизации междисциплинарных методов и подходов, рассмотрены примеры междисциплинарности в сфере выработки новых системных и авторских подходов и терминов в рамках международно-правовых исследований. Выводы: установлена сущностная связь между вопросами междисциплинарности и основаниями научной новизны, важных с точки зрения специфических отношений между теорией международного права и ее предметом.

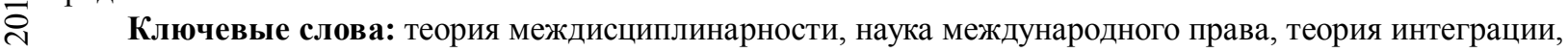
¿ профессиональные компетенции, проблемы высшего образования.

Цитирование. Каракулян Э. А. Методология междисциплинарных исследований и наука международного права // Legal Concept = Правовая парадигма. - 2019. - Т. 18, № 4. - C. 146-152. - DOI: https://doi.org/ 10.15688/lc.jvolsu.2019.4.20 


\section{Введение}

Понятие «междисциплинарность» используется в различных значениях и контекстах, главным образом в практическом и теоретическом отношении: а) инструмент в отношении предмета самого исследования; б) методология междисциплинарности. В первом случае мы смотрим на то, каким образом могут быть задействованы междисциплинарные подходы; в рамках одной тематики происходит выбор среди множества междисциплинарных подходов. Во втором речь идет о систематизации представлений относительно возможных структур междисциплинарных взаимодействий, характерных для исследований различной тематики, но имеющих общий междисциплинарный характер. Иными словами, мы сталкиваемся либо с практикой применения данного метода в конкретной работе, либо с теорией его применения в историческом, актуальном или перспективном преломлении. При этом исследователь должен решать, прямо или косвенно, вопросы связанные с методологией междисциплинарности.

\section{Краткий обзор основных позиций в истории и теории междисциплинарности}

В истории доктрин чем крупнее автор, тем явственнее его приверженность к междисциплинарному видению. Классические теоретики ставили основные вопросы, охватывающие многие (если не все) сферы жизни и мысли. Сознание древних было преимущественно синкретичным, и научное мышление, возникшее в процессе постепенного отдаления от начальной слитности знаний в сторону большей специализированности, но дистанцировавшееся от него не сразу. Долгое время оно сохраняло память о нем, хотя и формировалось в ситуации определенной полемики между научным и мифологическим сознанием. Сократ и ссылается на мифы, и критикует их. Платон в какой-то степени сам стремится к созданию новых мифов, реагируя на постсинкретический распад некогда единых знаний. При этом вслед за мифологическим мировоззрением возникало не столько науч- ное, сколько философское или метафизическое видение мира (если следовать периодизации эволюции знаний, предложенной О. Контом [5, с. 54]).

В эпоху Просвещения и Нового времени появляются современные представления о научности, основанной на опыте, эксперименте и соответствующих методах, то есть на так называемых «положительных знаниях». Одновременно работа ведется в направлении суммирования знаний не только в качестве обобщений в предметной сфере, но и в форме составления классификаций и энциклопедий. Формируются, сосуществуют и переплетаются два синхронных направления: наука ведет в сторону предметной специализации, а философия - универсализации знаний, когда выстраиваются определенные иерархии знаний и форм сознания и выводится общий концептуальный знаменатель для определенного множества или множеств знаний. Например, идея для Платона, поэтика для Дж. Вико («о поэтической метафизике», а также логике, морали, праве, экономике, астрономии, физике и др.); диалектика и философия в отношении права, морали, государства для Г.Ф. Гегеля; история для К. Маркса; общество для О. Конта и др. Такие концептуальные знаменатели создавали общую матрицу соответствующей теории, ее предмет и главенствующий метод. Философия стремилась объяснить мир «посредством какого-нибудь универсального принципа» [1, с. 111].

К началу XX в., после первого периода позитивистских дифференциаций и специализаций, стала осознаваться необходимость объединения и переработки знаний. А.А. Богданов в рамках «универсальной организационной науки» предложил специфическую концепцию синтеза знаний, которую ныне относят к предтече новейших исследований в области теории систем, кибернетики. Новая «постановка вопроса... в полной мере универсальна», охватывает «и практические, и теоретические методы, и сознательные человеческие, и стихийные методы природы. $<\ldots>$ вне такой интегральной постановки вопроса его решение невозможно, ибо часть, вырванная из целого, не может быть сделана целым или быть понята помимо цело- 
го» [1, с. 112]. Однако в действительности $\mathrm{XX}$ в. стал периодом дальнейшего дробления и специализации знаний, связанных с развитием прикладного позитивизма, различных направлений и ответвлений в рамках неопозитивизма.

\section{Междисциплинарность в рамках современных правовых исследований}

Говоря о междисциплинарности, стоит отметить, что речь идет не столько о синтезе знаний, сколько о построении отдельных междисциплинарных связей. В рамках юриспруденции обращение к междисциплинарности обосновывается необходимостью выхода за строгие рамки правовой догматики [7].

Реализация междисциплинарности ведет к появлению так называемых «бинарных юридических дисциплин», «специальных юридических наук, предметное поле которых состоит из двух и более наук» (криминология, криминалистика, право социального обеспечения), заимствованию из смежных дисциплин «категориального ряда, концепций и методов», когда «методам проведения юридических исследований внимание вообще не уделяется» [7]. Происходит «формирование специальных дисциплин междисциплинарного характера (история права, философия права, социология права, юридическая политология, правовая кибернетика, юридическая антропология, юридическая логика, правовая статистика, юридическая лингвистика и т. д.)». Наблюдается процесс «формирования новых полей междисциплинарности, в которых представления о материнских отраслях знаний полностью размывается (“гибридные” отрасли исследования: гендерные исследования, исследования городской среды, исследования преступности)» [7]. Они имеют значимость по доминантной технике исследования или по специфике предметного поля [7].

Исследователи отмечают, что новая междисциплинарная парадигма должна включать «социальные отношения и различие между экономическим обменом, моральными обязательствами и правовой системой» [7]. Отсюда право понимается либо как система «ожиданий поведения других агентов», либо как «основание социального порядка». Отме- чается, что «степень действенности закона необходимо обсуждать не только с позиций междисциплинарного описания и объяснения, но также с учетом ее взаимосвязи и взаимозависимости с юридическим межотраслевым измерением и результативностью» [3, с. 108].

Междисциплинарность через нестандартный объект исследования ведет к «интенсивному размыванию традиционного поля» науки, а дифференциация знаний - к ситуации потери взаимопонимания. Создается «угроза существованию истории как отдельной, самостоятельной дисциплины» [10]. Подобную аналогию можно представить в правовых исследованиях, а равно и возможные опасения по этому поводу.

С другой стороны, необходимо отметить «малый эффект междисциплинарности», то есть «механическое соединение методов разных наук», «эффект описательности». «Принцип междисциплинарности нередко только декларируется, а не применяется на практике» $[10$, c. 103]. Высказываются опасения относительно «методологического эклектизма»: «Невозможно достичь удовлетворительного понимания общественной жизни или эффективно воздействовать на нее, если не располагаешь синтетической картиной, позволяющей ввести в единые рамки результаты, полученные в самых различных областях» [6, с. 22].

Иными словами, междисциплинарность используется либо слабо, либо без соответствующей методологической рефлексии, угрожает предметному полю традиционных дисциплин, создает новые предметные поля без четко очерченных границ. Проблема такова: с одной стороны, она должна следовать за дисциплинарностью, а соединение разных дисциплин - быть не механическим и эклектичным; с другой - исследование должно быть выдержанно в собственных предметно-методологических рамках, чтобы иметь выходы на определенные результаты. Как представляется, следует говорить не только о соединении дисциплин, но и о разных сторонах последних в их взаимосвязи. Это может послужить предпосылкой органичности и снятия опасности в отношении предметно-методологической чистоты исследования, поскольку данный синтез будет происходить на основе внутренних соответствий отдельных сторон 
категориального аппарата, логических операций, методик и методов.

Например, понятие «системы» в историческим плане трансформируется в понятие «процесс, ведущий к созданию системы», «процесс систематизации»; аналогично «конституция» - «процесс, ведущий к созданию констиуционных структур, конституциализация» [13], «согласование воль» - «процесс гармонизации», а «процесс формирования субъекта»- «процесс персонализаųuи» (от фр. personnalité - юридическое лицо). Поэтому подобные смыслы в процессуальном измерении можно смело, но теоретически ответственно, переносить из одной сферы в другую, в данном случае - из сферы внутреннего права в сферу международного в той степени, в какой может быть обнаружено сходство между законами развития социумов разных уровней.

Любая система права, сама отличительность правовых систем зависят преимущественно от способа юридизации социальной жизни, поскольку последняя - есть объект для регулирования со стороны правовых механизмов. Характер данной системе, то есть отличительность, задает именно соответствующий ей способ юридизации социальной сферы. В этом смысле процессы (помимо специфических) могут быть общими для разных социумов, а конкретная механика их протекания, превращающая социальную сферу в правовую - качественно различной. В каждой правовой системе есть собственные субъекты и их статусы, распределение последних по роли и месту, а также нормы и иерархия норм: по отношению и к внутреннему, и к международному правам можно говорить, что на определенном уровне обобщений наблюдается сходство процессов субъектообразования (персонализации) и конституциализации, в то время как механизм нормообразования различен. При этом следует отличать процесс превращения социальной сферы в правовую, зависящий от целой совокупности факторов, в широком смысле и процесс, замыкающийся на механике нормообразования, действия норм и санкций за их нарушение, в узком.

Приведем другой пример: в рамках интеграционных исследований, в силу интегра- ционности самого предмета, происходит сочетание самых различных методов анализа, основными из которых являются системный и процессуальный, а также находящийся на пересечении первых двух метод идентификации [4, с. 25]. Данная форма междисциплинарности частично может быть использована при рассмотрении любого типа объединительных процессов - на уровне людей, государств, обществ и др., поскольку интеграция как предмет - есть событие интегрального построения, для которого в любом измерении необходимо использование интегральных методов.

Таким образом, характер предмета определяет характер метода («с чего начинается самый материал, должна была бы разумно начинаться и... наука» [2, с. 401]): междисциплинарный предмет влечет за собой появление междисциплинарного метода, интеграционный характер предмета - интегральный метод. Следовательно, существует нечто общее между теорией интеграции государств и собственно методологией междисциплинарности и, если шире, теорией интеграции знаний. Это означает, что помимо изначальных структур, в основе которых находятся государственные образования и институты, существуют вертикальные и горизонтальные отношения и структуры - межгосударственные и надгосударственные, аналогично в сфере дисциплин междисциплинарные и наддисциплинарные. С появлением компонента «над» возникают дополнительные теоретические проблемы, так как при движении от нижних этажей к верхним возможны необратимые изменения, когда части растворяются и исчезают в целом. Решение этих вопросов связано с тем, как мы понимаем суть интеграционности. Если интеграция - это «движение к целому», то ее теория не мыслима без основных представлений и знаний по философии и диалектики целого с их законами и особенностями. В связи с этим смысл интеграции уже не представляет собой простой союз (ассоциацию), простое слияние (ассимиляцию), или характер конгломеративного образования. Более того, интеграционный процесс и предмет существуют лишь до тех пор, пока сохраняются различия между основными элементами, что предполагает вертикальную и горизонтальную дифференциацию: различия между структурами 


\section{МЕЖДУНАРОДНОЕ ПРАВО И СРАВНИТЕЛЬНОЕ ПРАВОВЕДЕНИЕ}

и уровнями их отношений - отношений типа «интер» и «над». В этом смысле слияние в единое построение может рассматриваться как результат и завершение процесса интеграции, а в рамках целого или движения к нему можно констатировать о множестве единств, то есть систем, подсистем и механизмов функционирования.

\section{Цели и стратегии системы образования}

Специалисты утверждают, что с одной стороны, «возрастает потребность в людях, обладающих нестандартным мышлением, ориентированных на творческую инициативу, конкурентоспособность, мобильность, свободное развитие», делается акцент на «системной целостности качеств (компетенций)», с другой - ФГОС третьего поколения, ориентирован «на компетентностный подход, который сегодня находится в духе тренда исследования прикладного аспекта образования применительно к запросам экономики и общества». В исследованиях отмечается, что «когитарно-предметное содержание образования дополняется надпредметным содержанием» [8, с. 7], но каким образом это происходит, не раскрывается. Возникает вопрос: как соотносится «надпредметное содержание» (то есть знание интегрального типа) с функциональными и специализированными по своему характеру «запросами экономики и общества»? В этом обнаруживается оппозиция между характерами узкого специалиста и адепта интегральных знаний, сущностное противостояние которых скрывается, умалчивается или просто декларируется обратное.

Социальное предназначение системы образования не должно заключаться в предоставлении услуг и производстве предметных (узкопредметных) специалистов. Именно стратегийно-ценностное, а не конъюктурно-прикладное значение образования может вести к формированию интегральных знаний или творчески ориентируемых специалистов. Каким бы ни был конкретный способ междисциплинарности (от аналогии, метода исторической синхронии, биографического метода, до так называемого метода символико-событийного сквозного анализа), творчески ориентиру- емый синтез знаний сопряжен с разработкой авторского видения. Это предполагает сочетание явных и неявных знаний [9, с. 209], альтернативных или экспериментальных способов анализа, подходов и позиций, необходимых для развития научных школ. Последнее в свою очередь касается вопроса как о социальном статусе научного работника, находящегося либо в условиях стабильности и преемственности, либо в ситуациях прекарности [11, с. 106], так и о допустимой степени наукоемкости авторских курсов в образовательном процессе.

Междисциплинарный метод должен быть предметным (иметь свой предмет), и эта предметность - связана с расширением границ той сферы знаний, в которой разворачивается, что не может быть результатом математических или формально-логических вычислений, так как речь идет не о расширении за счет смежных отраслей, а направлений еще не охваченных теорией знаний. Естественно, результат, характеризуемый появлением нового, не может быть с точностью прогнозирован, так как зависит от множества факторов и отношений. Но любая практика или даже попытка концептуализации на грани сложившихся категорий создает условия для потенциального появления нового если не предмета, то ракурса в его отношении (хотя новое возникает в архаических формах прежде, чем быть включенным в актуальные структуры знаний и стать фактом консенсуса внутри научного сообщества).

В рамках науки международного права междисциплинарность приобретает важную особенность, будучи одним из главных факторов, создавших международное право [12]. Данный тезис о том, что наука формирует свой предмет, коррелируется с положением о международном праве, формирующем международное сообщество.

\section{Выводы}

Развитие междисциплинарных исследований в сфере науки международного права связано с решением проблемы нового, совершенствованием системы общего и специального образования. Однако это представляется необходимым как для самой науки, так и для компетентного и эффективного воздей- 
ствия на ее предмет, в основе которого - регулирование международных отношений, поиск оптимальных и более упорядоченных форм международной жизни, по своей природе связанных с фундаментальными и устойчивыми структурами мирного состояния международного сообщества.

\section{СПИСОК ЛИТЕРАТУРЫ}

1. Богданов, А. А. Тектология: (Всеобщая организационная наука). В 2 кн. Кн. 1 / А. А. Богданов. - М. : Экономика, 1989. -304 с.

2. Вико, Д. Основания новой науки об общей природе наций / Д. Вико. - М. ; Киев : REFL-book : ИСА, 1994. $-656 \mathrm{c}$.

3. Графский, В. Г. О междисциплинарном подходе в изучении права и законов / В. Г. Графский // Контуры глобальных трансформаций: политика, экономика, право. - 2012. - Вып. 4. - Электрон. текстовые дан. - Режим доступа: https:// cyberleninka.ru/article/v/o-mezhdistsiplinarnompodhode-v-izuchenii-prava-i-zakonov (дата обращения: 04.08.2019). - Загл. с экрана.

4. Каракулян, Э. А. Европейский неофедерализм: процесс, система, идентичность : учеб. пособие / Э. А. Каракулян. - Н. Новгород : Изд-во ННГУ, 2003. $-208 \mathrm{c}$.

5. Конт, О. Дух позитивной философии. (Слово о положительном мышлении) / О. Конт. - Ростов н/Д : Феникс, 2003. -256 с.

6. Леонтьев, В. Экономические эссе. Теории, исследования, факты и политика / В. Леонтьев. М. : Политиздат, 1990. - 415 c.

7. Минькова, А. М. «Междисциплинарные исследования в юриспруденции» для слушателей программы «Междисциплинарное индивидуальное гуманитарное образование» / А. М. Минькова. - Электрон. текстовые дан. - Режим доступа: http://uchebana5.ru/cont/2651216.html (дата обращения: 04.08.2019). - Загл. с экрана.

8. Покровская, Е. М. Междисциплинарные подходы в обеспечении образовательного процесса в вузе: основные тенденции, цели, задачи. Научно-педагогическое обозрение / Е. М. Покровская, М. Ю. Раитина, О. В. Горских. - Pedagogical Review. - 2014. - № 2 (4). - C. 7-13.

9. Современная западная философия : словарь / сост.: В. С. Малахов, В. П. Филатов. -М. : Издво полит. лит-ры, 1991. -414 с.

10. Теория и методология истории : учеб. и практикум для академ. бакалавриата / А. И. Филюшкин [и др.] ; под ред. А. И. Филюшкина. -М. : Юрайт, 2016. -323 с.
11. Тощенко, Ж. Т. Прекариат: от протокласса к новому классу : монография / Ж. Т. Тощенко. М. : Наука, 2018. - 350 c.

12. Энциклопедический словарь Брокгауза и Ефрона. - Электрон. текстовые дан. - Режим доступа: : http://niv.ru/doc/dictionary/brockhaus-efron/ articles/204/mezhdunarodnoe-pravo.htm (дата обращения: 20.08.2019). - Загл. с экрана.

13. Gaudin, H. Amsterdam : l'échec de la hiérarchie des normes? / H. Gaudin // Revue trimestrielle de droit européen. - 1999. - № 35 (1). - P. 1-20.

\section{REFERENCES}

1. Bogdanov A.A. Tektologiya: (Vseobshchaya organizatsionnaya nauka). V2-kn.: Kn. 1 [Tectology: (General Organizational Science). In 2 books. Book 1]. Moscow, Ekonomika Publ., 1989. 304 p.

2. Viko D. Osnovaniya novoy nauki ob obshchey prirode natsiy [Foundations of a New Science on the Common Nature of Nations]. Moscow; Kiev, REFLbook Publ., ISA Publ., 1994. 656 p.

3. Grafskiy V.G. O mezhdistsiplinarnom podkhode $\mathrm{v}$ izuchenii prava i zakonov [On an Interdisciplinary Approach to the Study of Law and Laws]. Kontury globalnykh transformatsiy: politika, ekonomika, pravo [Contours of Global Transformations: Politics, Economics, Law], 2012, iss 4. URL: https://cyberleninka.ru/article/v/omezhdistsiplinarnom-podhode-v-izuchenii-prava-izakonov (accessed 4 August 2019).

4. Karakulyan E.A. Evropeyskiy neofederalizm: protsess, sistema, identichnost : ucheb. posobie [European Neo-Federalism: Process, System, Identity. Textbook]. Nizhny Novgorod, Izd-vo NNGU, 2003. $208 \mathrm{p}$.

5. Kont O. Dukh pozitivnoy filosofii. (Slovo o polozhitelnom myshlenii) [The Spirit of Positive Philosophy. (A Word About Positive Thinking)]. Rostov-on-Don, Feniks Publ., 2003. 256 p.

6. Leontyev V. Ekonomicheskie esse. Teorii, issledovaniya, fakty i politika [Economic Essays. Theories, Studies, Facts and Politics]. Moscow, Politizdat Publ., 1990. 415 p.

7. Minkova A.M. "Mezhdistsiplinarnye issledovaniya $v$ yurisprudentsii» dlya slushateley programmy «Mezhdistsiplinarnoe individualnoe gumanitarnoe obrazovanie» ["Interdisciplinary Research in Jurisprudence" for Students of the Program "Interdisciplinary Individual Humanitarian Education"]. URL: http://uchebana5.ru/cont/ 2651216.html (accessed 4 August 2019).

8. Pokrovskaya E.M., Raitina M.Yu., Gorskih O.V. Mezhdistsiplinarnye podkhody $\mathrm{v}$ obespechenii obrazovatelnogo protsessa v vuze: osnovnye 


\section{МЕЖДУНАРОДНОЕ ПРАВО И СРАВНИТЕЛЬНОЕ ПРАВОВЕДЕНИЕ}

tendentsii, tseli, zadachi. Nauchno-pedagogicheskoe obozrenie [Interdisciplinary Approaches to Ensuring the Educational Process at the University: Main Trends, Goals, Objectives. Scientific and Pedagogical Review]. Pedagogical Review, 2014, no. 2 (4). pp. 7-13.

9. Malakhov V.S., Filatov V.P. Sovremennaya zapadnaya filosofiya : slovar [Modern Western Philosophy. Dictionary]. Moscow, Izd-vo polit. litry, 1991.414 p.

10. Filyushkin A.I. et. al. Teoriya $i$ metodologiya istorii: uchebnik i praktikum dlya akademicheskogo bakalavriata [Theory and Methodology of History. Textbook and Workshop for Academic Undergraduate]. Moscow, Yurayt Publ., 2016. 323 p.

11. Toshchenko Zh.T. Prekariat: ot protoklassa $k$ novomu klassu : monografiya [Precariate: from Protoclass to New Class. Monograph]. Moscow, Nauka Publ., 2018. 350 p.

12. Entsiklopedicheskiy slovar Brokgauza $i$ Efrona [Encyclopedic Dictionary of Brockhaus and Efron]. URL: http://niv.ru/doc/dictionary/brockhausefron/articles/204/mezhdunarodnoe-pravo.htm. (accessed 4 August 2019).

13. Gaudin H. Amsterdam : l'échec de la hiérarchie des normes? Revue trimestrielle de droit européen, 1999, no. 35 (1), pp. 1-20.

\section{Information about the Author}

Emil A. Karakulyan, Candidate of Sciences (Jurisprudence), Associate Professor, Department of European and International Law, Lobachevsky State University of Nizhni Novgorod, Ashkhabadskaya St., 4, 603115 Nizhny Novgorod, Russian Federation, isoforoma@yahoo.fr, keimp.c@yandex.ru, https://orcid.org/0000-0003-0761-6601

\section{Информация об авторе}

Эмиль Альбертович Каракулян, кандидат юридических наук, доцент кафедры европейского и международного права, Национальный исследовательский Нижегородский государственный университет им. Н.И. Лобачевского, ул. Ашхабадская, 4, 603115 г. Нижний Новгород, Российская Федерация, isoforoma@yahoo.fr, keimp.c@yandex.ru, https://orcid.org/0000-0003-0761-6601 